\title{
Effect of the Physicochemical Properties of Soils on Generalized and Localized Corrosion Rate of API X52 and X60 Pipeline Steels
}

\section{Contreras A* \\ Instituto Mexicano del Petróleo, México}

*Corresponding author: Antonio Contreras, Instituto Mexicano del Petróleo, Eje Central Lázaro Cárdenas Norte 152, Col. San Bartolo Atepehuacan, C.P. 07730, CDMX, Mexico, Tel: +52 5591758194; Email: México.acontrerascuevas@gmail.com

\section{Research Article}

Volume 5 Issue 1

Received Date: December 28, 2020

Published Date: January 18, 2021

DOI: $10.23880 /$ ppej-16000246

\section{Abstract}

This work analyzed physicochemical properties of different types of soils on the generalized and localized corrosion rate in two steels (X52 and X60) most used in pipeline transportation of hydrocarbons. The physicochemical properties such moisture content, $\mathrm{pH}$, resistivity and redox potential, which influence the corrosion rate of the pipelines were analyzed. Soils from three different sites in the south of México were obtained. Soils were sampled approximately $1.5 \mathrm{~m}$ deep, close to pipeline. From the analysis of generalized corrosion results taking into account the type of soil, it was observed that the most corrosive soil for the two steels was soil-3, generating corrosion rates of 0.119 and $0.097 \mathrm{~mm} / \mathrm{year}$, for the X52 and X60 steels respectively, after a period of 6 months. It is important to note that the maximum generalized corrosion rate was obtained after 1 month of exposure of the steels, generating corrosion rates of 0.177 and $0.162 \mathrm{~mm} /$ year, for the X52 and X60 steels respectively. In similar way, the localized corrosion rates for the both steels were higher when steels are exposed to Soil-3, generating corrosion rates of 1.1 and $0.45 \mathrm{~mm} /$ year, for X52 and X60 steel respectively, after a period of 6 months. In general it was observed that X60 steel presents greater resistance to pitting corrosion rate (in Soil-3), which can be attributed to its more homogeneous microstructure, fine grain size, and its chemical composition that presents elements such as $\mathrm{Cr}$ and $\mathrm{Ni}$ in greater quantity than X52 steel, which improve the corrosion resistance. However, depending on the type of soil the corrosion resistance behavior of each steel is different. From the analysis of various equations fits, it was determined that the potential equation is the one that gives the best fit for all cases.

Keywords: Soils; Pipeline steels; Corrosion rate; Pitting

\section{Introduction}

The research on external corrosion originated by different types of soils in the current days have become of interest in the oil industry. The occurrence of external corrosion depends of many factors such as type of soil, moisture content, $\mathrm{pH}$, resistivity, redox potential, concentration of dissolved ions, cathodic protection, and microstructure of steel [1-3]. Investigations about pipelines that have developed external corrosion include a wide range of diameters, wall thicknesses, and grades. External corrosion has been found to occur in pipelines in contact with different types of soils with different moisture content.
Soils are considered the most complex electrolyte than other such as air and water $[4,5]$.

External corrosion has the following characteristics: the electrolyte is the soil, the electrolyte is static, the corrosion rate is related to ionic content, $\mathrm{pH}$, resistivity, and redox potential, among others; the corrosion product passivates the metal surface of the pipeline and the location of the corrosion damage is highly dependent on the coating damage in pipelines. All the main API pipeline steels (X52, X56, $\mathrm{X} 60, \mathrm{X} 65, \mathrm{X} 70$ and X80) used for oil and gas transmission pipelines are susceptible to external corrosion. Slightly lower corrosion rate observed on some of the most recent pipes 


\section{Petroleum \& Petrochemical Engineering Journal}

grades might be due to metallurgical factors, better coating systems, or improvement in the cathodic protection systems $[6,7]$.

Mexico is a country with a wide variety of soils and climates; it is possible to find soils like clays, silt, loam, sand with different environmental conditions (cold, hot, mild, wet, and warm climates); also it is possible to find rainy zones mainly in the Gulf of Mexico and the Pacific where they are large bodies of water, rivers and lagoons.

Because of its diversity as well as the short time in order to characterize all the soils, this work proposed to characterize three typical soils of ROW of pipelines in Mexico and use these in corrosion evaluations on X52 and X60 pipeline steels. Understanding how the physicochemical properties of different soils affect the corrosion rate (generalized and localized) was developed.

\section{Experimental}

In the oil industry within the sector of hydrocarbon transportation by pipelines, the main problem is external corrosion; which depends on the physicochemical factors of the soil such as $\mathrm{pH}$, resistivity, redox potential, humidity, ions, among others. Therefore, in this research work it is proposed to study the effect of the main physicochemical properties of the soils on the corrosion rate of steels used in the transport of hydrocarbons. For this purpose, two different API steel were considered (X52 and X60). It was proposed to design an experimental system consisting of 3 different types of soils and 2 grades of steels exposed to different periods of time $(1,2,4,8$ and 24 weeks), in order to determine how physicochemical properties of soils influence in the evaluation of the corrosion rate.

\section{Steels Used}

The materials used in this study were API 5L X52 and X60 pipeline steel, obtained from pipelines which have an external diameter of $914.4 \mathrm{~mm}$ (36 in) and $1066.8 \mathrm{~mm}$ (42 in); wall thickness of $9.5 \mathrm{~mm}$ ( $0.375 \mathrm{in})$ and $12.5 \mathrm{~mm}$ ( $0.5 \mathrm{in})$ respectively. The chemical composition of both steel used is shown in Table 1.

\begin{tabular}{|c|c|c|c|c|c|c|c|c|c|c|c|c|c|}
\hline Steel & $\mathbf{C}$ & $\mathbf{M n}$ & $\mathbf{S i}$ & $\mathbf{P}$ & $\mathbf{S}$ & $\mathbf{A l}$ & $\mathbf{N b}$ & $\mathbf{C u}$ & $\mathbf{C r}$ & $\mathbf{N i}$ & $\mathbf{M o}$ & $\mathbf{V}$ & $\mathbf{T i}$ \\
\hline X52 & 0.08 & 1.06 & 0.26 & 0.019 & 0.003 & 0.039 & 0.041 & 0.018 & 0.002 & 0.019 & 0.05 & 0.05 & 0.002 \\
\hline X60 & 0.02 & 1.57 & 0.14 & 0.013 & 0.002 & 0.046 & 0.099 & 0.3 & 0.26 & 0.17 & 0.05 & 0.002 & 0.014 \\
\hline
\end{tabular}

Table 1: Chemical composition of API X52 and X60 pipeline steel (wt \%).

Typical microstructure of low carbon steels includes pearlite and ferrite mainly. X52 steel has yield strength of 392 $\mathrm{MPa}$ and ultimate tensile strength of $498 \mathrm{MPa}$. Meanwhile, X60 steel has yield strength of $467 \mathrm{MPa}$ and ultimate tensile strength of $565 \mathrm{MPa}$.

\section{Soil sampling}

Three different soils of the South of México were used in this study. Much of the pipelines carrying oil are in the south of México and pass through several states, which was the reason to focus the study on these soils. Two soils are from Veracruz State (Soil-1 and Soil-2) close to Gulf of Mexico; and one soil from Oaxaca State (Soil-3) close to Pacific Ocean. Figure 1 shows a map placing the 3 point of soil sampling.

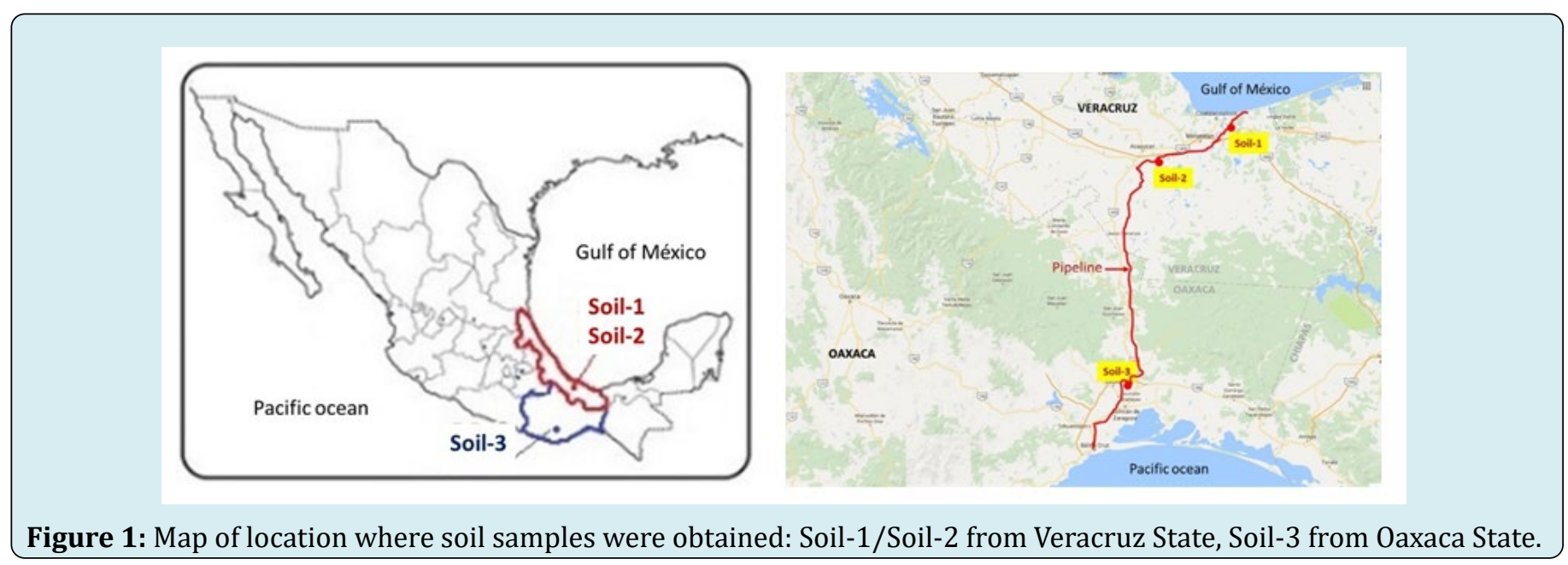




\section{Petroleum \& Petrochemical Engineering Journal}

The soil samples used for experiments were collected in field on the right of way of pipelines in the States of Veracruz and Oaxaca. Typically, soil samples were obtained at $1.5 \mathrm{~m}$ of depth, very close to pipelines. It should be noted that these sites were chosen based on the fact that in these locations Mexican pipelines have frequently presented failures due to external corrosion. Physical appearance of these soils is shown in Figure 2. Physicochemical parameters of these soils were measured in field, such as $\mathrm{pH}$, resistivity, redox potential and moisture content. Additionally, these physicochemical properties were measured each week in the experimental system in the lab.
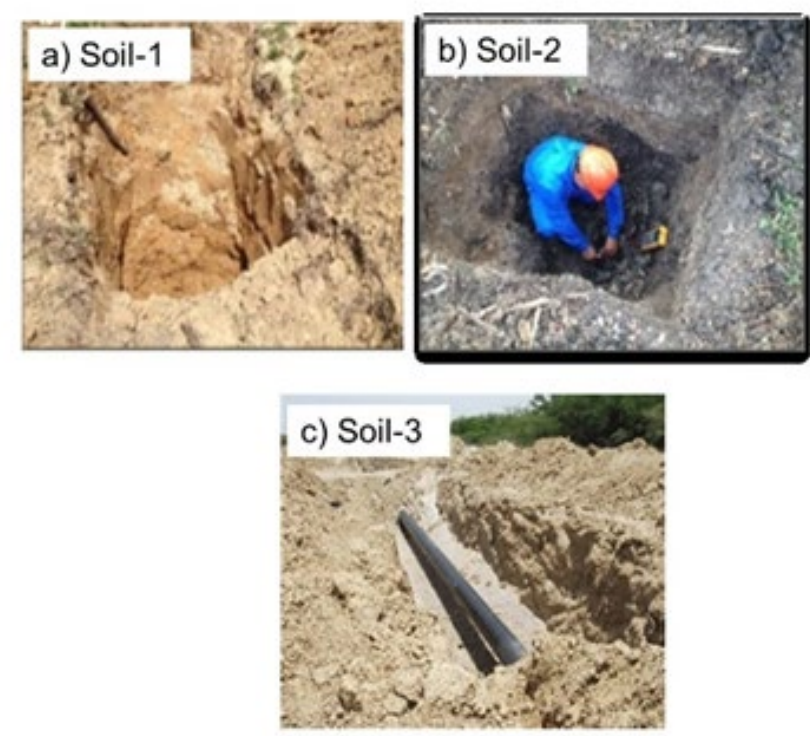

Figure 2: Physical appearance of soils a) Soil-1, and b) Soil-2 obtained from Veracruz State; and c) Soil-3 obtained from Oaxaca State.

\section{Textural Analysis of Soils}

Texture of the soils was determined by the Bouyoucos method [8]. This method is based on Stokes law, which establishes a relationship between particle size and the rate of sedimentation. The names of textural soil classes are given based on the analysis of the contents of clay, silt and sand. The relationship between the basic textural classes and the percentages of clay, silt and sand are indicated in a triangular figure according to the International System Reference for Soils adopted by the food and agriculture organization (FAO), but using grain size thresholds from United States Department of Agriculture (USDA).

The hydrometer method was used to determine the soil particle-size distribution. Texture, or size distribution of mineral particles (or its associated pore volume), is one of the most important measures of a soil because finely divided soil particles have much greater surface area per unit mass or volume than do coarse particles. Thus, a small amount of fine clay and silt will be much more important in chemical reactions, release of nutrient elements, retention of soil moisture, etc., than a large volume of coarse gravel or sand.

\section{Experimental System}

The soils obtained from field were used to assemble the experimental set-up. Three polyethylene tubes with each soil were prepared as is shown in Figure 3. At least two coupons from each steel (X52 and X60) were buried in each soil.

Once the coupons were buried, the experimental system for each soil was added with water according to the rainfall recorded daily by the meteorological system closest to the site where the soil was sampled. The coupons were removed after 1, 2, 4, 8, 12 and 24 weeks of exposure for cleaning as is shown in Figure 4. 


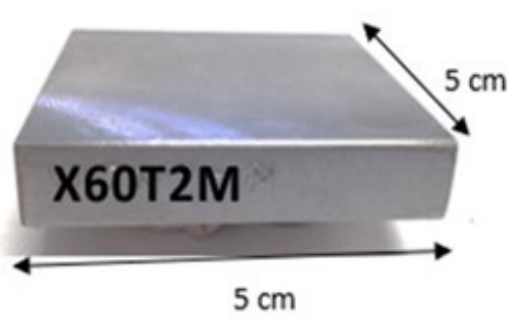

a)

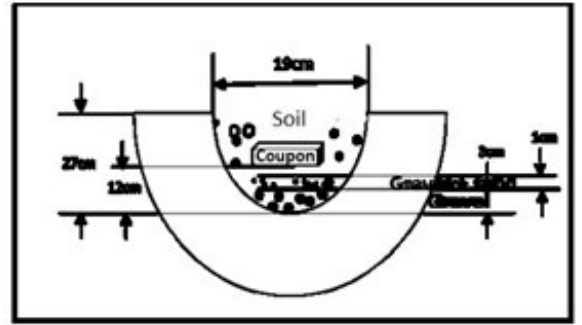

b)

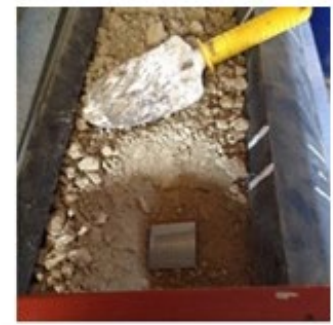

c)

Figure 3: a) Coupon machined from X60 steel, b) schematic of stratus soil, c) buried coupon.
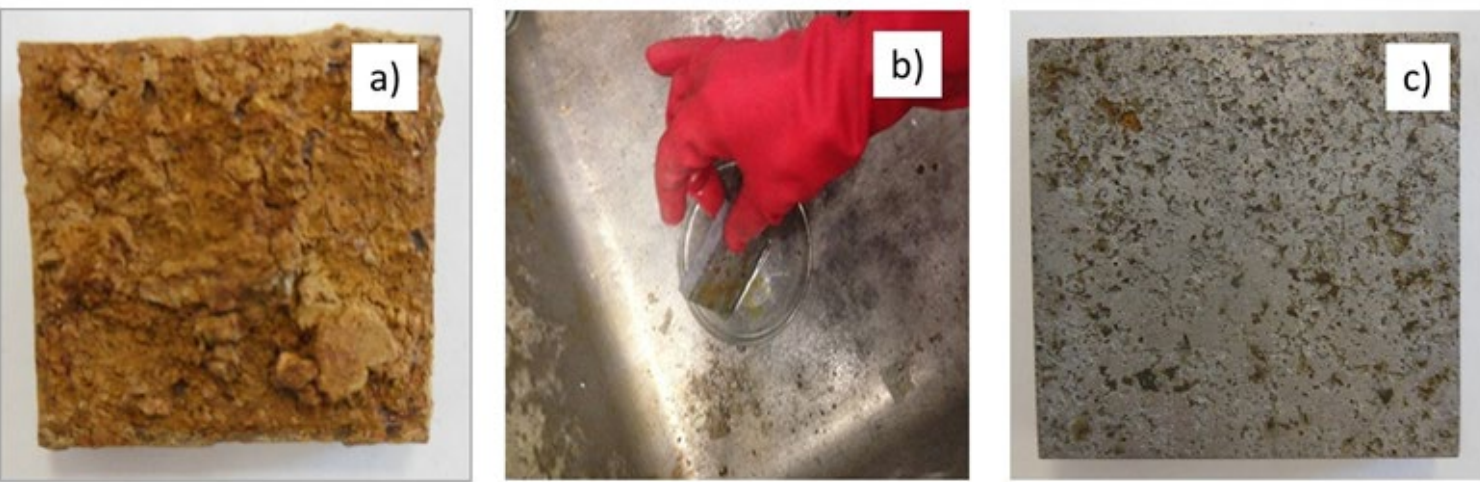

Figure 4: a) Coupon extracted before cleaning, b) chemical coupon cleaning, c) clean coupon.

\section{Corrosion Rate Measurement}

The corrosion rate was measured by two forms: 1) by weight loss (general corrosion) and 2) localized corrosion by depth of pits. With the data of the weights obtained, the general corrosion rate (CR) is calculated according to the formula indicated by the ASTM G31 standard [9]:

$$
C R=\frac{(\text { Initial weight }- \text { Final weight })(\text { Conversation factor })}{(\text { Area })(\text { Density })(\exp \text { osuretime })}
$$

With the maximum depth of the pit and the exposure time, the localized corrosion rate is calculated with the following formula:

$$
C R=\frac{d(\text { depth of pit })}{t(\exp \text { osuretime })}
$$

At least five pits were measured by each side of coupons. For the analysis of corrosion rate, the most depth pit was considered. Measurements of depth pits using a micrometer as is shown in Figure 5 was carried out.

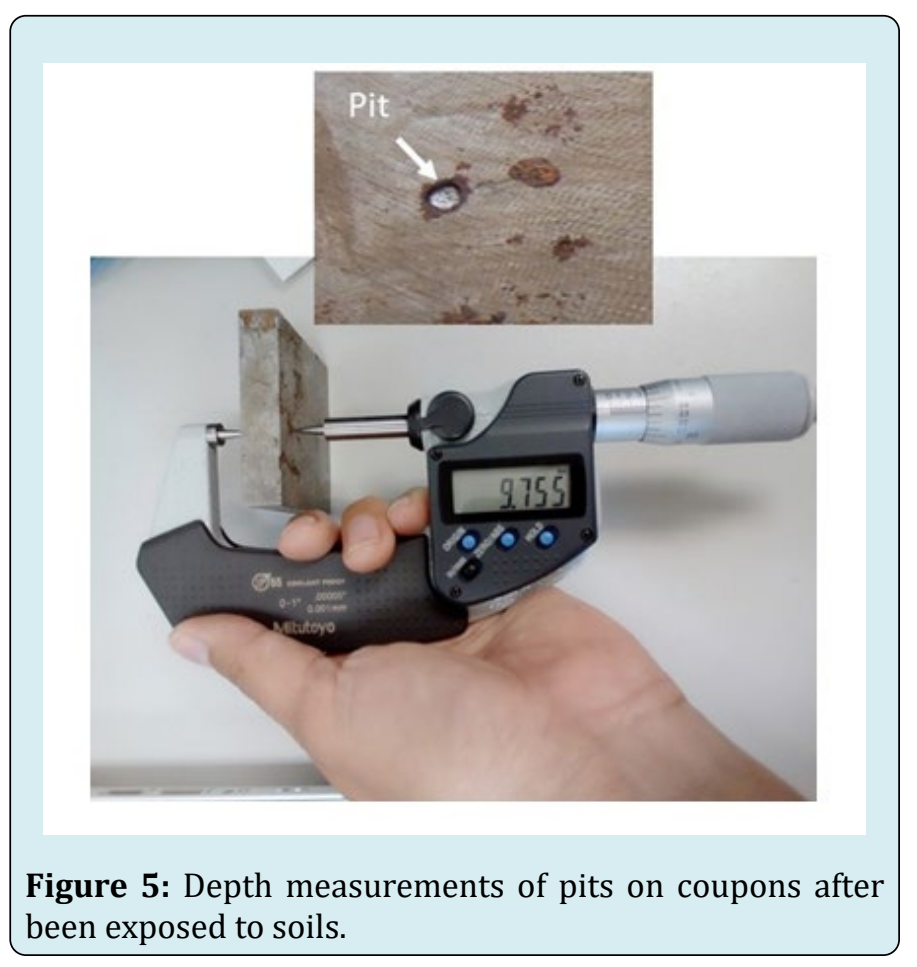




\section{Petroleum \& Petrochemical Engineering Journal}

The steel electrodes exposed to Soil-3, in general showed generalized corrosion type. Meanwhile the soil-1 produce localize corrosion in form of pitting on both steels. Most of the low carbon steels have some inclusions, such as $\mathrm{MnS}, \mathrm{SiO}_{2}, \mathrm{TiO}_{2}$, and $\mathrm{Al}_{2} \mathrm{O}_{3}$ mainly. Nucleation pits at these sites may have been enhanced by galvanic coupling between inclusions and the base metal, and the dissolution of the inclusions by the surrounding environment.

Microstructure of steel has been considered like one critical factor affecting corrosion initiation and propagation. Generally, inclusions of $\mathrm{Al}_{2} \mathrm{O}_{3}, \mathrm{MnS}$ and $\mathrm{SiO}_{2}$ are common in pipeline steels. Another phenomenon that local pitting corrosion can propitiate is stress corrosion cracking (SCC), which can be initiated from the bottom of a pit, but there is a morphological factor and critical pit size combined with the stresses to enhance transition from pitting to crack [1013]. When the soil is highly corrosive, preferentially pits are formed, which is attributed to dissolution process removing stress raisers from the pit bottom.

\section{Equation Adjustment to Determine Localized Corrosion Rate}

After performing the localized corrosion rate calculations for time of $1 \mathrm{~W}, 2 \mathrm{~W}, 4 \mathrm{~W}, 8 \mathrm{~W}$ and 24 weeks, an analysis of various equations fits was carried out to determine the best fit and obtain a general equation that would allow us to predict corrosion rate for longer times.

\section{Results and Discussion}

\section{Microstructural Characterization of Steels}

Figure 6 shows the typical microstructure for API X52 and X60 pipeline steels, which are composed of ferrite (light phase) and perlite (dark phase). Perlite is formed by layers of ferrite and cementite. X60 steel has a more homogenous perlite distribution around the grain boundaries. Meanwhile, X52 steel has more visible perlite colonies.
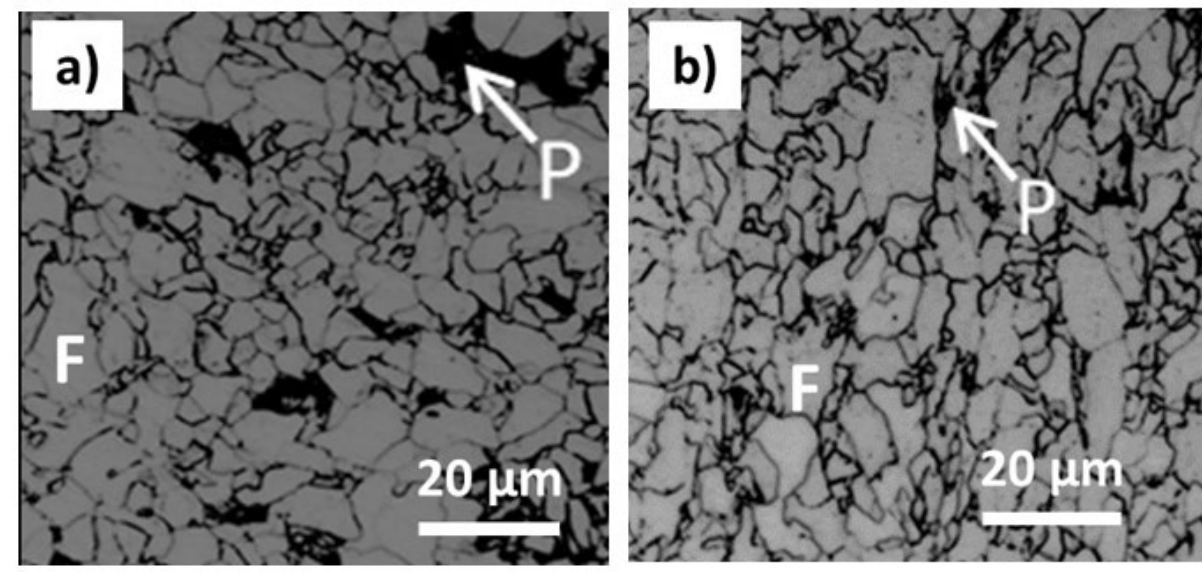

Figure 6: Microstructure of API X52 and X60 steels obtained by optical microscopy.

\section{Soil Texture}

Three different soils from South of Mexico were used in this study. Two soils (Soil-1 and Soil-2) were sampled from a right of way located in Veracruz State, close to Minatitlan City in the Gulf of Mexico. Other soil (Soil-3) was sampled in the right of way located in Oaxaca State, close to Salina Cruz City in the Pacific Ocean of Mexico. Table 2 shows the percentage of each texture and the corresponding type of soil obtained by the Bouyoucos method [8].

\begin{tabular}{|c|c|c|c|c|}
\hline & Sand & Clay & Silt & \\
\hline Soil & $(\%)$ & $(\%)$ & $(\%)$ & Type of soil \\
\hline Soil-1 & 42 & 38 & 20 & Sandy \\
\hline Soil-2 & 7 & 77 & 16 & Clay \\
\hline Soil-3 & 36 & 29 & 35 & Sandy-Loam \\
\hline
\end{tabular}

Table 2: Soil texture obtained by Bouyoucos method for each soil. 


\section{Petroleum \& Petrochemical Engineering Journal}

The names of textural soil classes are given based on the analysis of the contents of clay, silt and sand. Soil mineralogy plays a key role in the chemistry of associated groundwater in contact with underground pipelines. Clays especially have notably adsorption and retention of water. Parameters such as soil mineralogy and soil texture can influence the level of oxygenation (aerobic versus anaerobic), the soil drainage, and the tendency to promote coating disbondment.

\section{Physicochemical Properties of Soils}

Physicochemical parameters related to soil corrosion such as $\mathrm{pH}$, resistivity $(\rho)$, redox potential (Eredox) and moisture content were evaluated during sampling in field. These parameters are shown in Table 3. Additionally, theses physicochemical properties in pilot experimental system each week were measured. One of the main physicochemical parameters related to corrosivity is resistivity of the soil. According to NOM-08-SECRE and NRF-047-Pemex [14,15], resistivity values lower than $1000 \mathrm{Ohm} \cdot \mathrm{cm}$ belong to highly corrosive soils, between 1000 and $5000 \mathrm{Ohm} \cdot \mathrm{cm}$ belong to corrosive soils. Resistivity values greater than 10,000 $\mathrm{Ohm} \cdot \mathrm{cm}$ belong to slightly corrosive soils. Considering the redox potential, values higher than $400 \mathrm{mV}$ the probability of presence of sulphate reducing bacteria (SRB) is scarce [16].

Traditionally it has been taken as criterion that the soil resistivity is a main indicator of the steel corrosion in pipeline buried, however a soil with low $\mathrm{pH}$, high humidity and aerated could be a corrosive soil even if it has a high resistivity value. This combination of factors influencing the corrosion of steels.

\begin{tabular}{|c|c|c|c|c|}
\hline Soil & pH & $\rho(0 \mathrm{hm} \cdot \mathrm{cm})$ & Eredox (mV) & Moisture Content (\%) \\
\hline Soil-1 & 6.4 & 582 & 408 & 14 \\
\hline Soil-2 & 7.8 & 231 & 490 & 25 \\
\hline Soil-3 & 7.3 & 262 & 551 & 16 \\
\hline
\end{tabular}

Table 3: Physicochemical properties of soils measured in field.
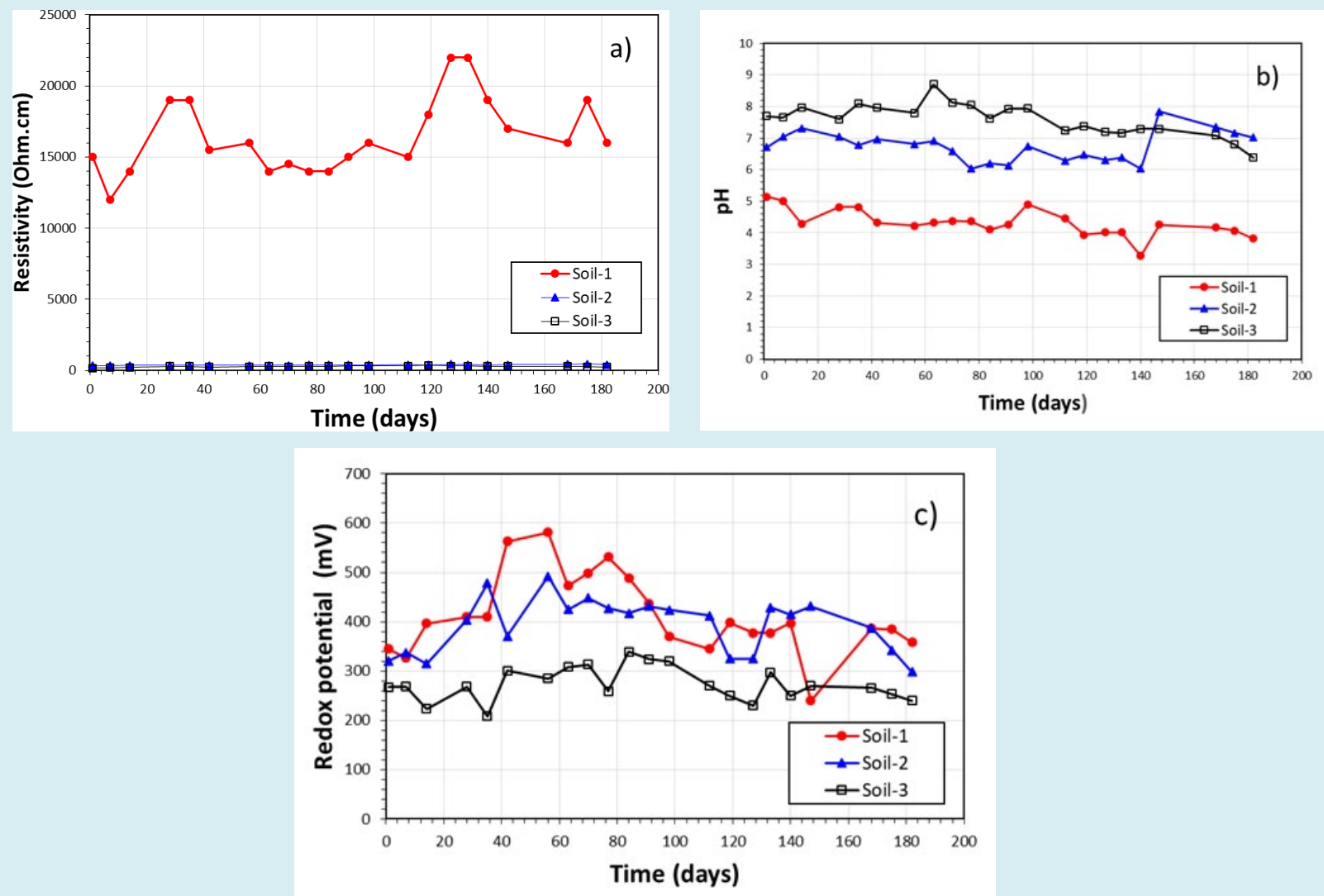

Figure 7: Physicochemical properties of the soils measured each week in the pilot experimental system, a) resistivity, b) pH and c) redox potential. 


\section{Petroleum \& Petrochemical Engineering Journal}

There are no published correlations between soil composition and corrosion except for some evidence that high chloride content promote development of pits. The ability of clay rich soils to adhere to surfaces can also aggravate coating damage caused by soil added on the structure. In extreme cases, shrinkage due to drying can lead to the formation of large scale cracks on the pipeline surface. For that reason seasonal variation in soil parameters is very important, because all the parameter related to corrosion are modified.

Figure 7 shows the physicochemical properties of the soils measured each week in the pilot experimental system. From figure $7 \mathrm{a}$ it is observed that soil- 2 and soil- 3 have lower resistivity values (less than $300 \mathrm{Ohm}-\mathrm{cm}$ ) typical of wet clay soils. Meanwhile, Soil-1 exhibit higher resistivity values, which are related to sandy soil. Figure $7 \mathrm{~b}$ show the $\mathrm{pH}$ values in function of time, which it is observed that soil- 1 exhibit the lower $\mathrm{pH}$ values (between 3-5). It is important to mention that soil-1 was obtained in a place with high organic content (garbage collector site). Soil-2 and Soil-3 have values close to neutral $\mathrm{pH}$. Figure $7 \mathrm{c}$ show the redox potential values, which it is observed that soil- 1 is the most aeriated soil. However, it is observed that all the soils have values between 200 $500 \mathrm{mV}$.

\section{Corrosion Rate Measurements}

Coupons were extracted from soils after 1, 2, 4, 8 and 24 weeks for evaluation. Once clean coupons, the corrosion rate was evaluated in two ways: 1) generalized corrosion due to loss of weight and 2) localized corrosion considering the depth of pitting. The soil physicochemical properties $(\mathrm{pH}$, resistivity and Redox potential) were correlated with the corrosion rates obtained. Figure 8 shows the general corrosion rate obtained by loss of weight of buried coupons in the three different soils for X52 and X60 steel. From this figure is clear that Soil-3 exhibit the highest corrosion rate, which may be correlated to higher moisture content and lower resistivity. Corrosion rate exhibit a sinusoidal behavior for the three soils. The highest corrosion rate was obtained after 4 weeks exposure for both steels. After this time the general corrosion rate trend to decrease, which can be attributed to passivation of steel surface.

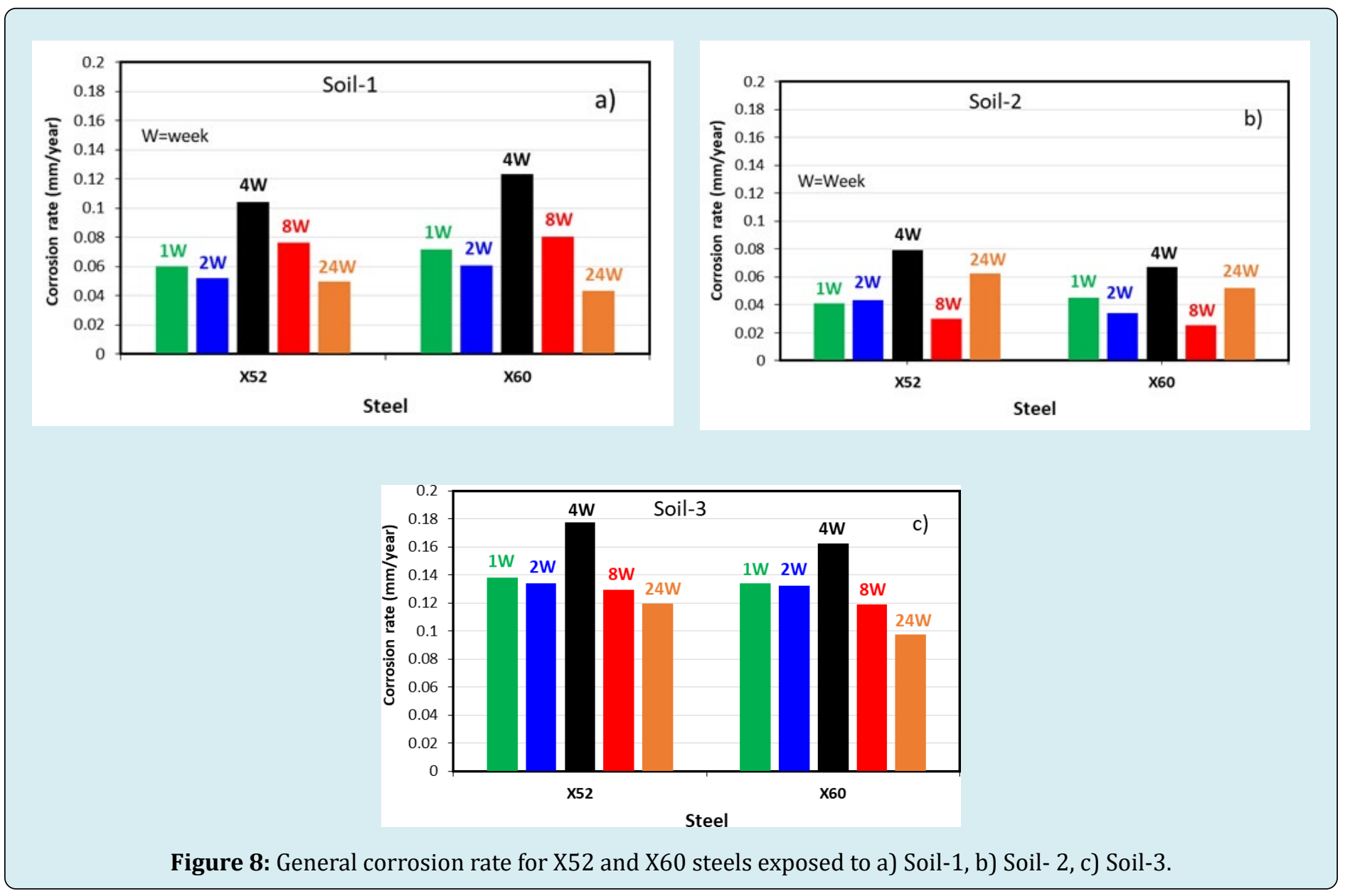


From the analysis of generalized corrosion results taking into account the type of soil, it was observed that the most corrosive soil for the two steels was soil-3, generating corrosion rates of 0.119 and $0.097 \mathrm{~mm} /$ year, for the X52 and X60 steels respectively, after a period of 6 months. In general, X60 steel has better resistance to generalized corrosion ( $0.097 \mathrm{~mm} / \mathrm{year})$, which can be attributed to its microstructure and its chemical composition that presents elements that provide resistance to corrosion, such as $\mathrm{Cr}$ and $\mathrm{Ni}$ in greater amount than X52 steel. It is important to note that the maximum generalized corrosion rate was obtained after 1 month of exposure of the steels, generating corrosion rates of 0.177 and $0.162 \mathrm{~mm} /$ year, for the X52 and X60 steels respectively.

For the analysis of localized corrosion, the depth of the pitting in the coupons was taken into account. For the X52 steel, the Soil-3 generated the deepest pits, reaching maximum pit depths of $0.26,0.27$ and $0.54 \mathrm{~mm}$ in Soil-2, Soil1 and Soil- 3 respectively, after 6 months of exposure. While for X60 steel the pit depths were more homogeneous in the three soils, with a slight tendency to generate greater depth pits in Soil-3, reaching maximum depths of $0.98 \mathrm{~mm}$ after 1 month of exposure.

From the analysis of localized corrosion results, it was observed that the corrosion rate decreases at as the exposure time increases, which can be attributed to the passivation of the steel by corrosion products adhering to the coupon surface.

Figure 9 shows the localized corrosion rate obtained by measuring the depth of pitting generated on buried coupons in the three different soils for X52 and X60 steel. From this figure is clear that Soil-2 and Soil-3 exhibit higher corrosion rate than Soil-1.
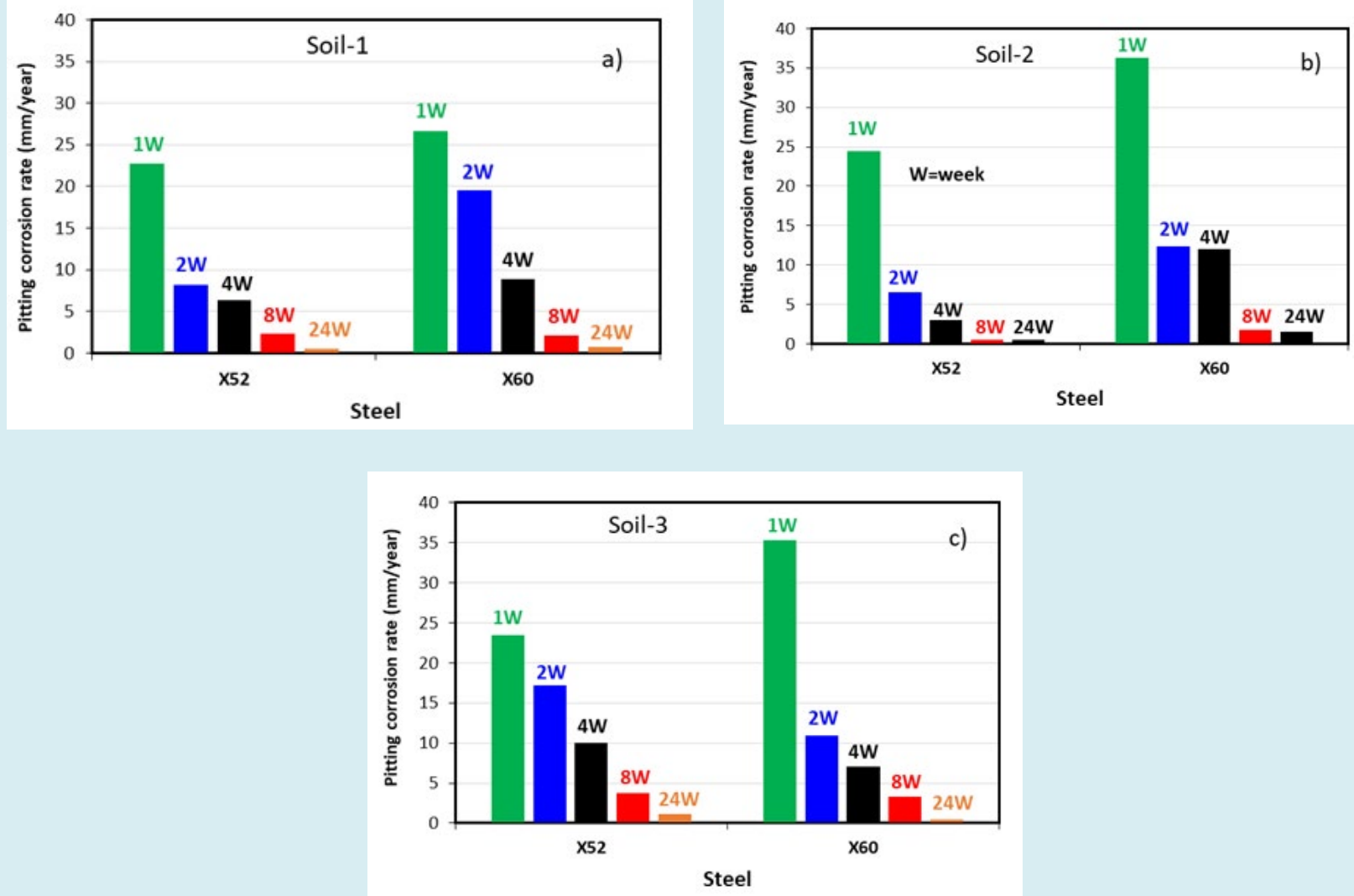

Figure 9: Localized corrosion rate for X52 and X60 steels exposed to a) Soil-1, b) Soil- 2, c) Soil-3.

The localized corrosion rates for the three steels were higher when steels are exposed to Soil-3, generating corrosion rates of 1.1 and $0.45 \mathrm{~mm} /$ year, for X52 and X60 steel respectively, after a period of 6 months. In general it was observed that X60 steel presents greater resistance to pitting corrosion rate (in Soil-3), which can be attributed to its more homogeneous microstructure, fine grain size, and its chemical composition that presents elements such as $\mathrm{Cr}$ 


\section{Petroleum \& Petrochemical Engineering Journal}

and $\mathrm{Ni}$ in greater quantity than X52 steel, which improve the resistance to corrosion. However, it is important to mention that depending on the type of soil the corrosion resistance behavior of each steel is different.

In summary, we can say that steels behave differently depending on the type of soil. According to these results we can say for example that in Soil-1 the best option is to use X52 steel in its pipelines, for the Soil-2 also the best option is to use X52 steel and finally for the Soil-3 the best option would be the X60 steel.

\section{Equation Adjustment to Determine Localized Corrosion Rate}

After performing the localized corrosion rate calculations for time of $1 \mathrm{~W}, 2 \mathrm{~W}, 4 \mathrm{~W}, 8 \mathrm{~W}$ and 24 weeks, an analysis of various equations fits was carried out to determine the best fit and obtain a general equation that would allow us to forecast corrosion rate for longer times. From the adjustments made, it was determined that the potential equation is the one that gives the best fit for all cases. Table 4 show the predicted corrosion rate values up to 10 -years for the three soils studied.

\begin{tabular}{|c|c|c|c|c|c|c|}
\hline \multirow{2}{*}{ Time (years) } & \multicolumn{2}{|c|}{ Soil-1 } & \multicolumn{2}{c|}{ Soil-2 } & \multicolumn{2}{c|}{ Soil-3 } \\
\cline { 2 - 7 } & $\mathbf{X 5 2}$ & $\mathbf{X 5 2}$ & $\mathbf{X 5 2}$ & $\mathbf{X 6 0}$ & $\mathbf{X 5 2}$ & X60 \\
\hline $0.0191(1 \mathrm{~W})$ & 22.7535 & 22.7535 & 17.489 & 31.3975 & 30.1952 & 35.329 \\
\hline $0.0383(2 \mathrm{~W})$ & 10.5918 & 10.5918 & 7.4113 & 15.5708 & 15.4079 & 14.7336 \\
\hline $0.0821(4 \mathrm{~W})$ & 4.5818 & 4.5818 & 2.8924 & 7.2197 & 7.371 & 5.6502 \\
\hline $0.1643(8 \mathrm{~W})$ & 2.1376 & 2.1376 & 1.2287 & 3.5877 & 3.7686 & 2.3623 \\
\hline $0.5(24 \mathrm{~W})$ & 0.6291 & 0.6291 & 0.3112 & 1.1685 & 1.2847 & 0.5832 \\
\hline 1 & 0.2937 & 0.2937 & 0.1323 & 0.581 & 0.6572 & 0.244 \\
\hline 2 & 0.1371 & 0.1371 & 0.0562 & 0.2889 & 0.3362 & 0.1021 \\
\hline 3 & 0.0878 & 0.0878 & 0.0341 & 0.192 & 0.2272 & 0.0613 \\
\hline 4 & 0.064 & 0.064 & 0.0239 & 0.1436 & 0.172 & 0.0427 \\
\hline 5 & 0.0501 & 0.0501 & 0.0182 & 0.1147 & 0.1386 & 0.0323 \\
\hline 6 & 0.041 & 0.041 & 0.0145 & 0.0955 & 0.1162 & 0.0257 \\
\hline 7 & 0.0346 & 0.0346 & 0.012 & 0.0817 & 0.1001 & 0.0211 \\
\hline 8 & 0.0299 & 0.0299 & 0.0102 & 0.0714 & 0.088 & 0.0179 \\
\hline 9 & 0.0263 & 0.0263 & 0.0088 & 0.0634 & 0.0785 & 0.0154 \\
\hline 10 & 0.0234 & 0.0234 & 0.0077 & 0.057 & 0.0709 & 0.0135 \\
\hline
\end{tabular}

Table 4: Localized corrosion rate predicted for 10-year (mm/year).

\section{Conclusions}

The analysis of physicochemical properties of different types of soils on the generalized and localized corrosion rate in two steels (X52 and X60) most used in pipeline transportation of hydrocarbons can draw the following conclusions:

- From the analysis of generalized corrosion results it was observed that the most corrosive soil for the two steels was soil-3, generating corrosion rates of 0.119 and 0.097 $\mathrm{mm} /$ year, for the X52 and X60 steels respectively, after a period of 6 months.

- The maximum generalized corrosion rate was obtained after 1 month of exposure of the steels, generating corrosion rates of 0.177 and $0.162 \mathrm{~mm} /$ year, for the X52 and X60 steels respectively.

- Localized corrosion rates for both steels (X52 and X60) were higher when steels are exposed to Soil-3, generating corrosion rates of 1.1 and $0.45 \mathrm{~mm} /$ year, for X52 and X60 steel respectively, after a period of 6 months.

- In general it was observed that X60 steel presents greater resistance to pitting corrosion rate (in Soil-3), which can be attributed to its more homogeneous microstructure, fine grain size, and its chemical composition that presents elements such as $\mathrm{Cr}$ and $\mathrm{Ni}$ in greater quantity than X52 steel, which improve the resistance to corrosion.

- It was observed that depending on the type of soil the corrosion resistance behavior of each steel is different. That is to say, that steels behave differently depending on the type of soil.

- From the analysis of various equations fits, it was determined that the potential equation is the one that gives the best fit for all cases. 


\section{Petroleum \& Petrochemical Engineering Journal}

\section{References}

1. Quej-Ake LM, Contreras A, Liu HB, Alamilla JL, Sosa E (2018) Assessment on external corrosion rates for API pipeline steels exposed to acidic sand-clay soil. Anticorrosion Methods and Materials 65(3): 281-291.

2. Bradford SA (2001) Practical Handbook of Corrosion Control in Soils. Casti Publishing, Edmonton.

3. Quej-Ake LM, Marín-Cruz J, Contreras A (2017) Electrochemical study of the corrosion rate of API steels in clays soils. Anti-Corrosion Methods and Materials 64(1): 61-68.

4. Wilmott MJ, Jack TR (2011) Corrosion by Soils. In: Winston R (Ed.), Uhlig's Corrosion Handbook. $2^{\text {nd }}$ (Edn.), John Wiley \& Sons, Inc.

5. Uhlig HH, Revie RW (1985) Corrosion and Corrosion Control: An introduction to corrosion science and engineering. $4^{\text {th }}(E d n$.$) , Wiley, New York.$

6. Eckert RB (2017) Residual life predictions-extending service life. Trends in Oil and Gas Corrosion Research and Technologies, Woodhead Publishing Series in Energy, pp: 765-786.

7. John RC, Fort III WC (2001) Petroleum Industry: Corrosion. $2^{\text {nd }}(E d n)$, Encyclopedia of Materials: Science and Technology, pp: 6840-6842.

8. Bouyoucos GJ (1962) Hydrometer method improved for making particle size analysis of soils. Agronomy Journal 54(5): 464-465.

9. ASTM G31 (2004) Standard Practice for Laboratory Immersion Corrosion Testing of Metals.

10. Fang BY, Eadie RL, Chen WX, Elboujdaini M (2010) Pit to crack transition in $\mathrm{X}-52$ pipeline steel in near neutral $\mathrm{pH}$ environment Part 1-formation of blunt cracks from pits under cyclic loading. Corrosion Engineering Science and Technology 45(4): 302-312.

11. Van Boven G, Chen W, Rogge R (2007) The role of residual stress in neutral pH stress corrosion cracking of pipeline steels. Part I: Pitting and cracking occurrence. Acta Materialia 55(1): 29-42.

12. Hoeppner DW (1979) Model for prediction of fatigue lives based upon a pitting corrosion fatigue process. In: Fong J (Ed.), Fatigue Mechanisms, ASTM International, pp: 841-870.

13. Kondo Y (1989) Prediction of fatigue crack initiation life based on pit growth. Corrosion 45(1): 7-11.

14. NOM-008-SECRE-1999, Control de la corrosión externa en tuberías de acero enterradas y/o sumergidas.

15. NRF-047-Pemex-2007, Diseño, instalación y mantenimiento de los sistemas de protección catódica.

16. Ávila J, Genesca J (1989) Mas allá de la herrumbre. La lucha contra la corrosión. 